\title{
Does bank regulation and supervision impedes the efficiency of microfinance institutions to eradicate poverty? evidence from ASEAN-5 countries
}

\begin{abstract}
Purpose: The purpose of this study is to examine how banking regulation and supervision affect the performance of microfinance institutions (MFIs). It proposes performance of the MFIs from the aspect of social and financial efficiency because the MFIs nowadays not only view to sustain the social role of poverty eradication but in the same time they must strive the financial sustainability to maintain the operation in long run. This study also includes the macroeconomic condition and firm level variables to control for social and financial efficiency of the MFIs. Design/methodology/approach: The data consists 168 MFIs from five countries in Southeast Asia from year 2011 to 2017. First stage of analysis is to identify level of social and financial efficiency by using data envelopment analysis approach. Second stage is to examine impact of bank regulation and supervision to the social and financial efficiency by applying panel regression analysis and generalized method of moments for robust estimation methods. Findings: The finding shows the MFIs own lower social efficiency and higher score in financial efficiency. This indicates in pursuing financial sustainability, the MFIs in Southeast Asia countries have lost sight of their original mission of poverty reduction. Furthermore, the result also presents a significant impact of bank regulation and supervision to the social and financial efficiency of the MFIs. However, the results appear in different direction when more negative effect is associated with social efficiency. This specifies that bank regulation and supervision are not appropriate to accommodate the social needs, thus hampering the effort of poverty reduction by the MFIs. Research limitations/implications: The present study only concentrates on the impact bank regulation and supervision to the performance of the MFIs. As the operation of the MFIs currently has been largely exposed in banking operation, it is suggested that future studies to look for other special issues such as country governance that might influence specifically in social and financial aspect of the MFIs. Practical implications: The empirical findings from this study could be useful and may have significant implications for the regulators. The regulators or policymakers could establish the new regulation framework that fulfil the dual needs (social and financial) of the MFIs. Furthermore, the empirical findings also could serve as guidance to regulators and decision-makers in designing new policies for a sustainable and competitive sector of the MFIs. Although the MFIs recently brings a similar role as commercial banks, they need to retain the social aspects as that is the original mission of the MFIs. Originality/value: The present study proves that the bank regulation and supervision have brought a significant influence to the performance of the MFIs in ASEAN 5 countries.
\end{abstract}

Keyword: Poverty reduction; Social efficiency; Microfinance institutions; Financial efficiency; Bank regulation and supervision 